\title{
Elevated Apoptosis in the Liver of Dairy Cows with Ketosis
}

\author{
Xiliang Du ${ }^{a}$ Liang Chen ${ }^{b}$ Dan Huang ${ }^{a}$ Zhicheng Peng ${ }^{a} \quad$ Chenxu Zhao ${ }^{a}$ \\ Yuming Zhang ${ }^{\mathrm{a}}$ Yiwei Zhu ${ }^{\mathrm{a}}$ Zhe Wang ${ }^{\mathrm{a}}$ Xinwei Lia Guowen Liu ${ }^{\mathrm{a}}$ \\ aKey Laboratory of Zoonosis, Ministry of Education, College of Veterinary Medicine, Jilin University, \\ Changchun, Jilin, 'beilongjiang Institute of Veterinary Science, Qiqihar, Heilongjiang, China
}

\section{Key Words}

Ketotic cows $•$ Oxidative stress $\cdot$ Mitogen-activated protein kinase $\cdot$ Apoptosis

\begin{abstract}
Background/Aims: Dairy cows with ketosis are characterized by oxidative stress and hepatic damage. The aim of this study was to investigate hepatic oxidative stress and the apoptotic status of ketotic cows, as well as the underlying apoptosis pathway. Methods: The blood aspartate aminotransferase (AST), alanine aminotransferase (ALT), glutamate dehydrogenase (GLDH) and gamma-glutamyl transferase (GGT) activities and the haptoglobin (HP), serum amyloid A (SAA) and serum apoptotic cytokeratin 18 neo-epitope M30 (CK18 M30) concentrations were determined by commercially available kits and ELISA kits, respectively. Liver histology, TUNEL and Oil red $\mathrm{O}$ staining were performed in liver tissue samples. TG contents were measured using an enzymatic kit; Caspase 3 assays were carried out using the Caspase 3 activity assay kit; oxidation and antioxidant markers were measured using biochemical kits; apoptosis pathway were determined by qRT-PCR and western blot. Results: Ketotic cows displayed hepatic fat accumulation. The hepatic malondialdehyde (MDA) content was significantly increased, but the activities of catalase (CAT), superoxide dismutase (SOD) and glutathione peroxidase (GSH$\mathrm{Px}$ ) were markedly decreased in ketotic cows compared with control cows, indicating that ketotic cows displayed severe oxidative stress. Significantly higher serum levels of the hepatic damage markers AST, ALT, GGT and GLDH were observed in ketotic cows than in control cows. The blood concentration of the apoptotic marker CK18 M30 and the number of TUNEL-positive cells in the liver of ketotic cows were 1.19- and 2.61-fold, respectively, higher than the values observed in control cows. Besides, Caspase 3 activity was significantly increased in the liver of ketosis cows. Importantly, the levels of phosphorylated c-Jun N-terminal kinase (JNK) and p38 mitogen-activated protein kinase (p38MAPK) were significantly increased but the level of phosphorylated extracellular signal-regulated kinase1/2 (ERK1/2) was markedly decreased, which further promoted tumor protein 53 (p53) expression and inhibited nuclear factor E2related factor 2 (Nrf2) expression. The apoptosis-related molecules p21, MDM2, Caspase 3, Caspase 9 and Bax were expressed at significantly higher levels in ketotic cows than in healthy cows, whereas the anti-apoptosis molecule $\mathrm{Bcl}-2$ was expressed at significantly lower levels.
\end{abstract}

Xinwei Li,

and Guowen Liu 


\section{Cellular Physiology Cell Physiol Biochem 2017;43:568-578 \begin{tabular}{l|l|l|l} 
DOI: 10.1159/000480529 & O 2017 The Author(s). Published by S. Karger AG, Basel \\
wwww.karger.com/cpb
\end{tabular}

Conclusions: Based on these results, ketotic cows display severe hepatic oxidative stress. The hepatic MAPK-p53-Nrf2 apoptotic pathway is over induced and partially mediated apoptotic damage in the liver.

\section{Introduction}

The transition period between late pregnancy and early lactation is certainly a stage with a high incidence of nutrition-mediated metabolic diseases, such as ketosis and fatty liver, in dairy cows. Postpartum dairy cows are often in a state of negative energy balance (NEB) that is induced by a low intake of dry matter and an increased demand for energy to support milk production [1]. NEB initiates fat mobilization and a subsequent increase in the blood concentration of non-esterified fatty acids (NEFAs) and $\beta$-hydroxybutyrate (BHBA) [2]. According to Li et al., oxidative stress is observed in the postpartum and ketotic cows and is related to hyperketonemia and high NEFA levels [3].

Dairy cows with ketosis display high blood free fatty acid levels and hepatic lipid accumulation. Excessive hepatic lipid accumulation impairs mitochondrial function, energy metabolism, and cellular signal transduction, among other pathways (first hit) [4]. Furthermore, lipid accumulation results in reactive oxygen species (ROS) overproduction. Based on the results from human and mouse studies, high levels of ROS induce lipid peroxidation, changes in protein structural and strand breaks in nucleic acids to damage cells and organelles by altering cell membrane integrity and function, thereby inducing the "second hit" and resulting in apoptosis [5]. Apoptosis is a process by which cell death is initiated and completed in an orderly manner through the activation and/or synthesis of gene products necessary for cell destruction. Among these gene products, the mitogenactivated protein kinase (MAPK) family (c-Jun N-terminal kinase (JNK), extracellular signalregulated kinase 1/2 (ERK1/2) and p38 mitogen-activated protein kinase (p38 MAPK)), tumor protein p53 (p53), Bcl-2 family, and cysteine-dependent aspartate-specific proteases (Caspase) family play important roles in regulating apoptosis induced by various stresses [68]. ERK1/2, which is activated by growth factors, is required for cell survival by promoting proliferation, differentiation, and development [9]. In contrast, JNK and p38 MAPK are involved in apoptosis by increasing the cell death rate [10]. In human and mouse studies, the changes in MAPKs that are induced by many stimuli are influenced by the transcription or phosphorylation of the redox-sensitive transcription factors p53 and nuclear factor E2related factor 2 (Nrf2), contributing to the changes in the expression of downstream proapoptotic and anti-apoptotic genes [11, 12].

As shown in our previous studies, oxidative stress and hepatic damage occur in dairy cows with ketosis $[3,13]$. Importantly, Tharwat et al. reported that high levels of Caspase 3-positive and single-stranded DNA-(ssDNA)-positive cells in postpartum cows or cows with liver fatty infiltration in the liver, indicating that hepatocyte apoptosis is induced in dairy cows undergoing parturition or with fatty infiltration [14, 15]. Nevertheless, hepatic oxidative stress, the apoptotic status and changes in apoptotic pathways and apoptotic genes in ketotic cows were not evaluated in previous studies. The aim of this study was to investigate these parameters, to provide valuable information that will improve our understanding of the pathologic mechanism of ketosis.

\section{Materials and Methods}

\section{Animals}

The Ethics Committee on the Use and Care of Animals at Jilin University, Changchun, China approved the study protocol (2015 clinical trial [2015-121]). A routine physical examination was performed on each cow, including a determination of the rectal temperature, respiratory rate and pulse rate, to ensure the cows did not have other co-morbidities. We chose lactating Holstein cows from a 10, 000-cow dairy farm located 


\begin{tabular}{|c|c|c|c|c|}
\hline \multirow{2}{*}{$\begin{array}{l}\text { Table 1. Basic de- } \\
\text { scriptions of the } \\
\text { ketotic and healthy }\end{array}$} & & Ketosis $(\mathrm{n}=15)$ & Control $(\mathrm{n}=15)$ & $\mathrm{P}$ \\
\hline & Number of calves & $3.13 \pm 0.21$ & $2.87 \pm 0.23$ & 0.4125 \\
\hline cows (means \pm & Postpartum days & $5.6 \pm 0.5$ & $6.07 \pm 0.56$ & 0.5680 \\
\hline SEM) & Body weight (kg) & $578 \pm 32.1$ & $544 \pm 23.1$ & 0.0328 \\
\hline & Body condition scores & $3.12 \pm 0.16$ & $2.68 \pm 0.12$ & 0.0045 \\
\hline & Milk production ( $\mathrm{kg}$ of milk/cow per day) & $23.6 \pm 3.4$ & $28.3 \pm 2.5$ & 0.0014 \\
\hline & BHBA $(m M)$ & $2.4 \pm 0.17$ & $0.38 \pm 0.22$ & 0.0034 \\
\hline & NEFA $(m M)$ & $1.35 \pm 0.11$ & $0.33 \pm 0.02$ & $<0.0001$ \\
\hline & Glucose $(m M)$ & $2.13 \pm 0.08$ & $4.14 \pm 0.11$ & $<0.0001$ \\
\hline
\end{tabular}

Table 2. The basal diet formulation $\%$, *The premix provided the following per $\mathrm{kg}$ of diets: VA: 200,000 IU, VD: 70,000 IU, VE: 1,000 IU, Fe: 2,000 mg, Cu: 600 mg, Zn: 2,400 mg, Mn: 1,300 mg, I: 6 mg, Co: 7 mg

\begin{tabular}{lllllllll}
\hline Corn silage & Corn & Wheat bran & Soybean meal & Sunflower & $\mathrm{NaCl}$ & Premix & $\mathrm{NaHCO}_{3}$ & Total \\
\hline 40.00 & 35.00 & 8.00 & 5.00 & 8.00 & 1.00 & 1.80 & 1.20 & 100.00 \\
\hline
\end{tabular}

Table 3. Nutrient composition (\% of DM), DM, dry matter; NEL, net energy for lactation; $\mathrm{CP}$, crude protein; NDF, neutral detergent fiber; ADF, acid detergent fibre; NFC, non-fibre carbohydrate

\begin{tabular}{lllllll}
\hline NEL $(\mathrm{MJ} / \mathrm{Kg})$ & $\mathrm{CP}$ & $\mathrm{NDF}$ & ADF & NFC & Ca & P \\
\hline 6.70 & 15.20 & 33.45 & 17.20 & 40.40 & 0.70 & 0.50 \\
\hline
\end{tabular}

in Changchun City, Jilin Province, China. A basic description of the ketotic and healthy cows is provided in Table 1. Cows were fed a total mixed ration (TMR) ad libitum once per day at $1100 \mathrm{~h}$; the TMR met the animals' nutritional requirements [3]. The basal diet formulation was shown in Table 2 and 3. Several studies had reported that ketosis was defined as a serum BHBA > $1.2 \mathrm{mM}[16,17]$. Besides, serum glucose level was an auxiliary indicator in the diagnosis of ketosis. Therefore, according to the serum BHBA and glucose concentrations, thirty cows were divided into a healthy cow group (15 cows) and a ketotic (Type I) cow group (15 cows). In healthy cows, the serum BHBA concentration was less than $0.6 \mathrm{mM}$, the glucose concentration was higher than $3.75 \mathrm{mM}$. In ketotic cows, the serum BHBA concentration was greater than $1.2 \mathrm{mM}$, the glucose concentration was less than $2.5 \mathrm{mM}$.

Liver tissue samples (approximately $150 \mathrm{mg}$ ) were removed from the 11th or 12th right intercostal space by using a liver puncture needle (Shanghai Surgical Equipment Factory, Shanghai, China) after blood collection. Five liver samples from each group were dissected and most of each sample was fixed to perform liver histology, TUNEL staining and Oil red 0 staining; the remaining liver tissues were frozen in liquid nitrogen to extract total RNA and measure TG content. Ten liver samples from each group were frozen in liquid nitrogen to measure TG contents and Caspase 3 activity, analyze oxidation and antioxidant markers, and extract RNA and protein. During the experiments, cows were housed in a climate-controlled barn in individual tie stalls to reduce environmental effects.

\section{Blood samples and analytical procedures}

Blood samples were collected via coccygeal venipuncture at 3, 5, 7 and $9 \mathrm{~d}$ after calving before feeding and immediately centrifuged at $3,500 \mathrm{~g}$ for $15 \mathrm{~min}$ at $4{ }^{\circ} \mathrm{C}$. The serum was obtained, stored at $-80{ }^{\circ} \mathrm{C}$ and used to measure the levels of biochemical indicators end enzyme activities. Serum BHBA, NEFA and glucose levels were determined with a Hitachi 7170 autoanalyzer (Hitachi, Tokyo, Japan) using a commercially available kit (Randox Laboratories, Crumlin, UK). The activities of aspartate aminotransferase (AST), alanine aminotransferase (ALT), glutamate dehydrogenase (GLDH) and gamma-glutamyl transferase (GGT) were determined with an automatic biochemical analyzer (Sekisui Medical Co., Ltd., Tokyo, Japan) using commercially available kits (Randox Laboratories, Crumlin, UK). The concentrations of haptoglobin (HP) and 


\section{Cellular Physiology Cell Physiol Biochem 2017;43:568-578 \begin{tabular}{l|l|l} 
and Biochemistry & $\begin{array}{l}\text { DOI: 10.1159/000480529 } \\
\text { Published online: September 21, } 2017\end{array}$ & $\begin{array}{l}\text { C) } 2017 \text { The Author(s). Published by S. Karger AG, Basel } \\
\text { www.karger.com/cpb }\end{array}$
\end{tabular}}

Du et al.: Hepatic Apoptosis Status in Dairy Cows with Ketosis

serum amyloid A (SAA) were determined using ELISA kits (Shanghai Enzyme-linked Biotechnology Co., Ltd., Shanghai, China). The intra- and inter-assay coefficients of variation were $9.0 \%$ and $11 \%$ for HP, and $8.8 \%$ and $10.0 \%$ for SAA, respectively. Samples were analyzed in duplicate and absorbance values were measured at $450 \mathrm{~nm}$ for HP and SAA using a spectrophotometer (Thermo Scientific Instruments Inc., Shanghai, China). The minimum detection limit of these assays both were $10 \mathrm{ng} / \mathrm{L}$. Serum apoptotic cytokeratin 18 neo-epitope M30 (CK18 M30) levels were determined using an ELISA kit, according to the manufacturer's instructions with $450 \mathrm{~nm}$ (Shanghai Enzyme-linked Biotechnology Co., Ltd., Shanghai, China). The intra- and inter-assay coefficients of variation for M30 were $9.0 \%$ and $11 \%$ for M30, respectively.

\section{Liver histology}

Liver tissues were fixed with $10 \%$ formaldehyde in a neutral buffer solution, embedded in paraffin, and cut into $8 \mu \mathrm{m}$ sections. Liver sections were stained with hematoxylin/eosin (H\&E). For Oil red 0 staining, liver tissues were frozen in OCT compound (Sakura Finetek Co, Torrance, CA, USA), sectioned into $8 \mu \mathrm{m}$ slices at $-18^{\circ} \mathrm{C}$, stained with Oil red $\mathrm{O}$ (Sigma-Aldrich Co. St. Louis, MO, USA) and counterstained with hematoxylin.

\section{Measurement of liver TG contents}

TG contents were measured using an enzymatic kit (Applygen Technologies Inc., Beijing, China) following the manufacturer's instructions. The total protein concentration was estimated using the BCA method (Applygen Technologies Inc., Beijing, China), according to manufacturer's instructions.

\section{The analysis of hepatic oxidation and antioxidant markers}

Liver tissue specimens were crushed with a microthermal $\left(4{ }^{\circ} \mathrm{C}\right)$ tissue grinder (Shanghai Gino Tech \& Trading Co., Ltd., Shanghai, China), diluted with ice-cold phosphate buffered saline (PBS), and then centrifuged at $12,000 \mathrm{~g}$ for $10 \mathrm{~min}$ at $4{ }^{\circ} \mathrm{C}$. The supernatant was used to analyze the levels of oxidation and antioxidant markers. The malondialdehyde (MDA) content and the activities of catalase (CAT), superoxide dismutase (SOD) and glutathione peroxidase (GSH-Px) were measured using biochemical kits (Nanjing Jian Cheng Institute of Bioengineering, Nanjing, Jiangsu, China), according to the manufacturer's instructions. The MDA measurement was based on the reaction with thiobarbituric acid (TBA) in acidic media at $95{ }^{\circ} \mathrm{C}$ and was determined at $533 \mathrm{~nm}$. CAT activity was determined by measuring the decrease in $\mathrm{H}_{2} \mathrm{O}_{2}$ decomposition based on the absorbance at $240 \mathrm{~nm}$. SOD activity was determined at $550 \mathrm{~nm}$ using xanthine and xanthine oxidase systems. GSH-Px activity was detected by measuring the speed of GSH consumption, based on the reaction in which GSH is converted from its disulfide form (GSSG, glutathione disulfide) and $\mathrm{H}_{2} \mathrm{O}_{2}$ is simultaneously reduced to $\mathrm{H}_{2} \mathrm{O}$.

\section{Caspase 3 activity assay}

Caspase 3 assays were carried out using the Caspase 3 activity assay kit (Beyotime Biotechnology Inc., Shanghai, China) following the manufacturer's instruction. In brief, total protein concentration was estimated by the BCA method. Approximately $50 \mu \mathrm{g}$ protein was added to a reaction buffer containing AcDEVD-pNA ( $2 \mathrm{mM}$ ), incubated at $37^{\circ} \mathrm{C}$ for $4 \mathrm{~h}$, and the absorbance of yellow pNA was calculated with a spectrometer at $405 \mathrm{~nm}$. Caspase 3 activity was normalized to protein concentrations.

\section{TUNEL Staining}

Liver tissue specimens were fixed with $10 \%$ formaldehyde in a neutral buffer solution overnight and stored in 70\% ethanol. Samples were embedded in paraffin and sectioned at $5 \mu \mathrm{m}$ for processing for TUNEL staining using the Fluorescence and Colorimetric TUNEL Apoptpsis Assay Kit (Nanjing Jian Cheng Institute of Bioengineering, Nanjing, Jiangsu, China), following the manufacturer's instructions. Subsequently, the coverslips were sealed with glycerol, and the samples were observed under a laser confocal microscope (FV500, Olympus, Tokyo, Japan).

Quantitative real-time polymerase chain reaction ( $q R T-P C R$ )

Total RNA was extracted from the liver using RNAiso Plus (TaKaRa Biotechnology Co., Ltd., Dalian, China), according to the manufacturer's instructions. RNA concentrations and quality were determined using an RNA/DNA calculator (Biochrom, Cambridge, UK) and electrophoresis ( $1 \%$ agarose gels). Then, $5 \mu \mathrm{g}$ of total RNA were reverse-transcribed into cDNA using a reverse transcription kit (TaKaRa Biotechnology Co., 


\section{Cellular Physiology Cell Physiol Biochem 2017;43:568-578 and Biochemistry \begin{tabular}{l|l} 
DOI: 10.1159/000480529 & (c) 2017 The Author(s). Published by S. Karger AG, Basel \\
www.karger.com/cpb
\end{tabular}

Ltd., Dalian, China). We evaluated mRNA expression levels using qRT-PCR with the SYBR Green QuantiTect RT-PCR Kit (TaKaRa Biotechnology Co., Ltd., Dalian, China) and a 7500 Real-Time PCR System. The relative expression of each target gene was normalized to $\beta$-actin. qRT-PCR experiments were repeated fifteen times per group. The primers for each gene were designed using Primer Express software (PE Applied Biosystems, Inc., Foster City, CA, USA) and are listed as the following: p53: Forward, 5'-GCTTTGAGGTGCGTGTTT-3', and Reverse, 5'-GAGTGGGTGTTGGTAGGC-3'; Nrf2: Forward, 5'-GCCCTCACTGGATAAAGAA-3', and Reverse, 5'-CAT GCCGTTGCTGGTAC-3'; Bcl-2: Forward, 5'-TGACCGAGTACCTGAACCG-3', and Reverse, 5'-CAGCCAGGAGAAATC AAACA-3'; Bax: Forward, 5'-CAAACTGGTGCTCAAGGC-3', and Reverse, 5'-GCACTCCAGCCACAAAGAT-3'; Caspase 3: Forward, 5'-GAAGATGCTCCCAAGGC-3', and Reverse, 5'-CCAAGCGTCAAGTAAGAAGT-3'; Caspase 9: Forward, 5'-ATGGCAGACAGTCCTAGTAGCT-3', and Reverse, 5'-ATGGGTCACGGGCAAAA-3'; p21: Forward, 5'-CT GTGCGCAGATTCACGGAGA-3', and Reverse, 5'-ACAAAGTCGAAGTTCCACCGC-3'; MDM2: Forward, 5'-AAGAAGC CTAGTCTGAGGGGT-3', and Reverse, 5'-CGCTCGAACGCAGTAGATCC-3'; $\beta$-actin: Forward, 5'-GCCCTGAGGCTCTC TCCA-3', and Reverse, 5'-GCGGATGTCGACGTCACA-3'.

\section{Western blotting assay}

The total cellular proteins were extracted from the liver according to the manufacturer's instructions (Sangon Biotech Co., Ltd., Shanghai, China). The total protein concentration was estimated using the BCA method (Applygen Technologies Inc., Beijing, China), according to the manufacturer's instructions. Twenty micrograms of protein were separated on 12\% SDS-PAGE gels and then electrophoretically transferred to a PVDF membrane. Next, the membranes were blocked with 3\% bovine serum albumin (BSA) (SigmaAldrich Co. St. Louis, MO, USA). The blocked membranes were hybridized with primary antibodies against p38MAPK (Cat: 8690), p-p38MAPK (Cat: 4511), JNK (Cat: 9252), p-JNK (Cat: 9251), ERK1/2 (Cat: 9102), p-ERK1/2 (Cat: 4370), cleaved-Caspase 3 (Cat: 9661), phosphorylated p53 (Ser 15; Cat: 9284) (Cell Signaling Technology, Danvers, MA, USA), $\beta$-actin (Cat: ab8226), Caspase 9 (Cat: ab69514), Bcl-2 (Cat: ab692), Bax (Cat: ab32503), Nrf2 (Cat: ab31163) and p53 (Cat: ab26) (Abcam, Cambridge, UK;) overnight at $4{ }^{\circ} \mathrm{C}$, respectively. After 4 washes, membranes were incubated with horseradish peroxidase (HRP)-conjugated anti-rabbit or anti-mouse immunoglobulin (Beyotime Biotechnology Inc., Shanghai, China) for 45 min at room temperature. Immunoreactive bands were visualized with an enhanced chemiluminescence solution (ECL) (Beyotime Biotechnology Inc., Shanghai, China). Finally, the bands were imaged using a ProteinSimple imager (ProteinSimple, Santa Clara, CA, USA).

\section{Statistical analysis}

Data shown Table 4 were analyzed with a non-parametric test and expressed as medians and interquartile ranges. Other data were compared with a paired t-test and expressed as means \pm SEM. All data were analyzed using SPSS (Statistical Package for the Social Sciences) 19.0 software (SPSS Incorporated, Chicago, IL, USA). A $P$ value $<0.05$ was considered statistically significant and $P$ value $<0.01$ was marked significant compared to the control group.

Table 4. The blood concentrations of liver injury indicators and hepatic TG contents in ketotic and healthy cows

\begin{tabular}{llllll}
\hline & \multicolumn{2}{l}{ Ketosis $(\mathrm{n}=15)$} & \multicolumn{2}{l}{ Control $(\mathrm{n}=15)$} & $\mathrm{P}$ \\
& Median & $\mathrm{IQR}$ & Median & IQR & \\
\hline AST (U/L) & 160 & 143,168 & 85 & $75.1,88$ & $<0.0001$ \\
ALT (U/L) & 35.8 & $33.2,37.2$ & 22 & $19.1,24.8$ & $<0.0001$ \\
TG content (\% g/g of wet weight) & 5.8 & $3.95,6.71$ & 0.32 & $0.18,0.58$ & $<0.0001$ \\
HP (mg/mL) & 0.49 & $0.43,0.55$ & 0.14 & $0.13,0.2$ & $<0.0001$ \\
SAA ( $\mu \mathrm{g} / \mathrm{mL})$ & 89.2 & $83.76,96.72$ & 41.2 & $32,48.9$ & $<0.0001$ \\
GLDH $(\mathrm{U} / \mathrm{L})$ & 31.8 & $29.6,33.1$ & 18 & $15.6,22.3$ & $<0.0001$ \\
GGT $(\mathrm{U} / \mathrm{L})$ & 19.9 & $18.7,20.4$ & 11.3 & $10.1,12.8$ & $<0.0001$ \\
\hline
\end{tabular}




\section{Cellular Physiology

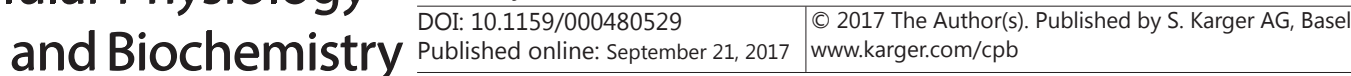 \\ Du et al.: Hepatic Apoptosis Status in Dairy Cows with Ketosis}

\section{Results}

Dairy cows with ketosis displayed hepatic oxidative stress and damage

Ketotic cows are characterized by high blood concentrations of NEFA and BHBA and hepatic TG accumulation. As shown in Table 4, the TG content of ketotic cows was much higher than control cows $(P<0.01)$. Moreover, according to the Oil red 0 and H\&E staining, the livers of ketotic cows displayed significantly increased lipid accumulation (Fig. 1). In addition, we determined the serum levels of the inflammatory markers HP and SAA and found that HP and SAA levels were significantly increased in ketotic cows (Table 4).

Furthermore, we detected the hepatic oxidative stress status in ketotic and healthy cows. As shown in Fig. 2A, the hepatic content of the oxidation indicator MDA was significantly increased in ketotic cows compared with control cows $(P<0.01)$. Conversely, the hepatic activities of the antioxidant enzymes CAT, GSH-Px, and SOD were significantly reduced in ketotic cows compared with control cows (Fig. $2 \mathrm{~B}, \mathrm{C}$ and D; $P<0.01$ ). Besides, as shown in Table 4, significantly higher AST, ALT, GLDH, and GGT levels were observed in ketotic cows than in control cows $(P<0.01)$, indicating that ketotic cows displayed severe hepatic damage.

\section{Ketotic cows displayed hepatic apoptosis}

We measured the serum M30 concentrations to investigate the apoptotic status of ketotic cows. As shown in Fig. 3A, a markedly higher M30 content was observed in ketotic cows (median: $268 \mathrm{U} / \mathrm{L}$; interquartile range: 175-357 U/L) than in control cows (median: 125 $\mathrm{U} / \mathrm{L}$; interquartile range: 80-168 U/L $(P<0.01)$. In addition, we measured the hepatic Caspase 3 activity to detect the hepatic apoptotic status of ketotic cows. The result showed that Caspase 3 activity was significantly increased in the liver of ketotic cows (Fig. 3B). TUNEL staining was performed on hepatic samples to further evaluate the apoptotic status of the

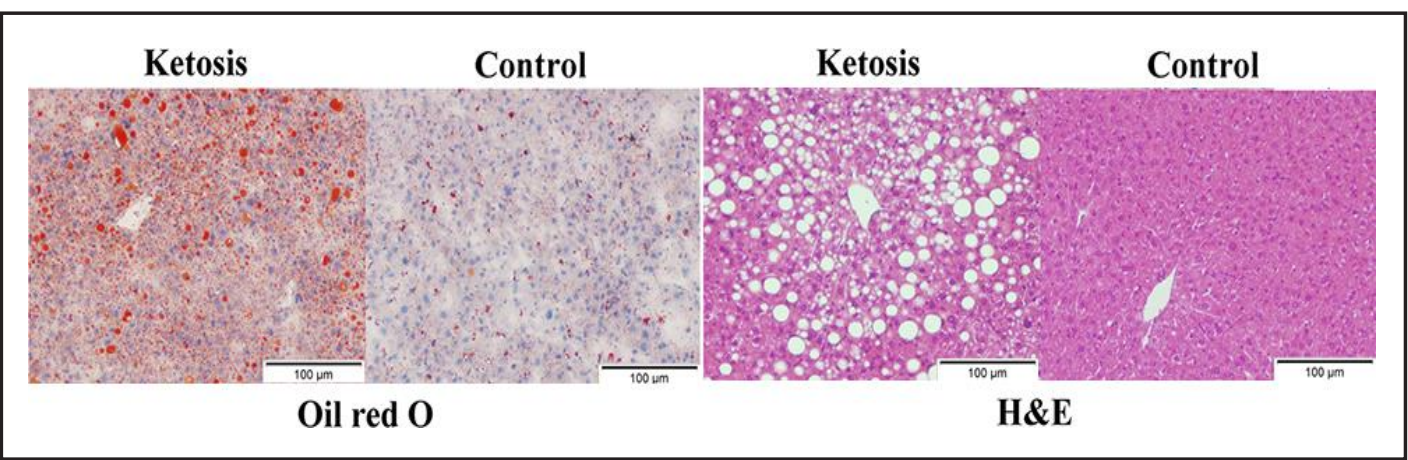

Fig. 1. Representative images of $\mathrm{H} \& \mathrm{E}$ and Oil red $\mathrm{O}$ staining of liver sections from ketotic and control cows. (Original magnification $\times 10$ ).
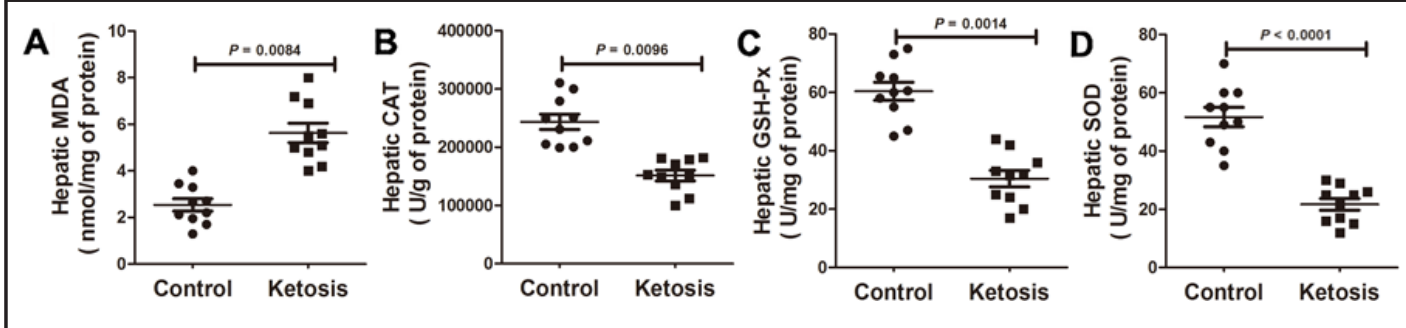

Fig. 2. Hepatic oxidative stress status of healthy and ketotic cows. A: Hepatic MDA content in ketotic ( $\mathrm{n}=$ $10)$ and healthy cows $(n=10)$; B-D: Hepatic CAT, GSH-Px and SOD activities in ketotic $(n=10)$ and healthy cows $(n=10)$. The data are presented as the means \pm SEM. 
Fig. 3. The blood concentration of apoptosis marker M30 and the hepatic Caspase 3 activity assay.A: The blood concentration of M30 in ketotic $(n=15)$ and healthy cows $(\mathrm{n}=15)$. The data presented are the median and interquartile ranges. B: The hepatic Caspase 3 activity in ketotic $(n=10)$ and healthy cows $(n=10)$. The data are presented as the means \pm SEM.
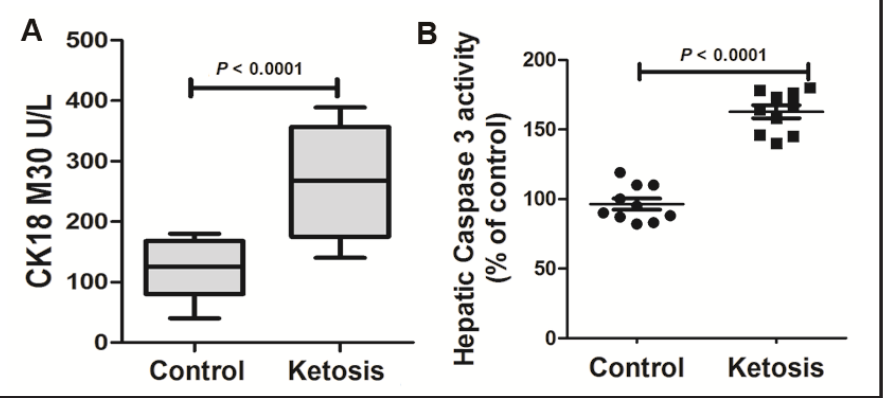

Fig. 4. Hepatic apoptosis status of healthy and ketotic cows. A. TUNEL staining in the livers of ketotic and healthy cows. Representative images of TUNEL-stained liver sections from ketotic and healthy cows. B. Quantification of the number of TUNEL-positive cells in liver sections from ketotic and healthy cows. The data are presented as the means \pm SEM.
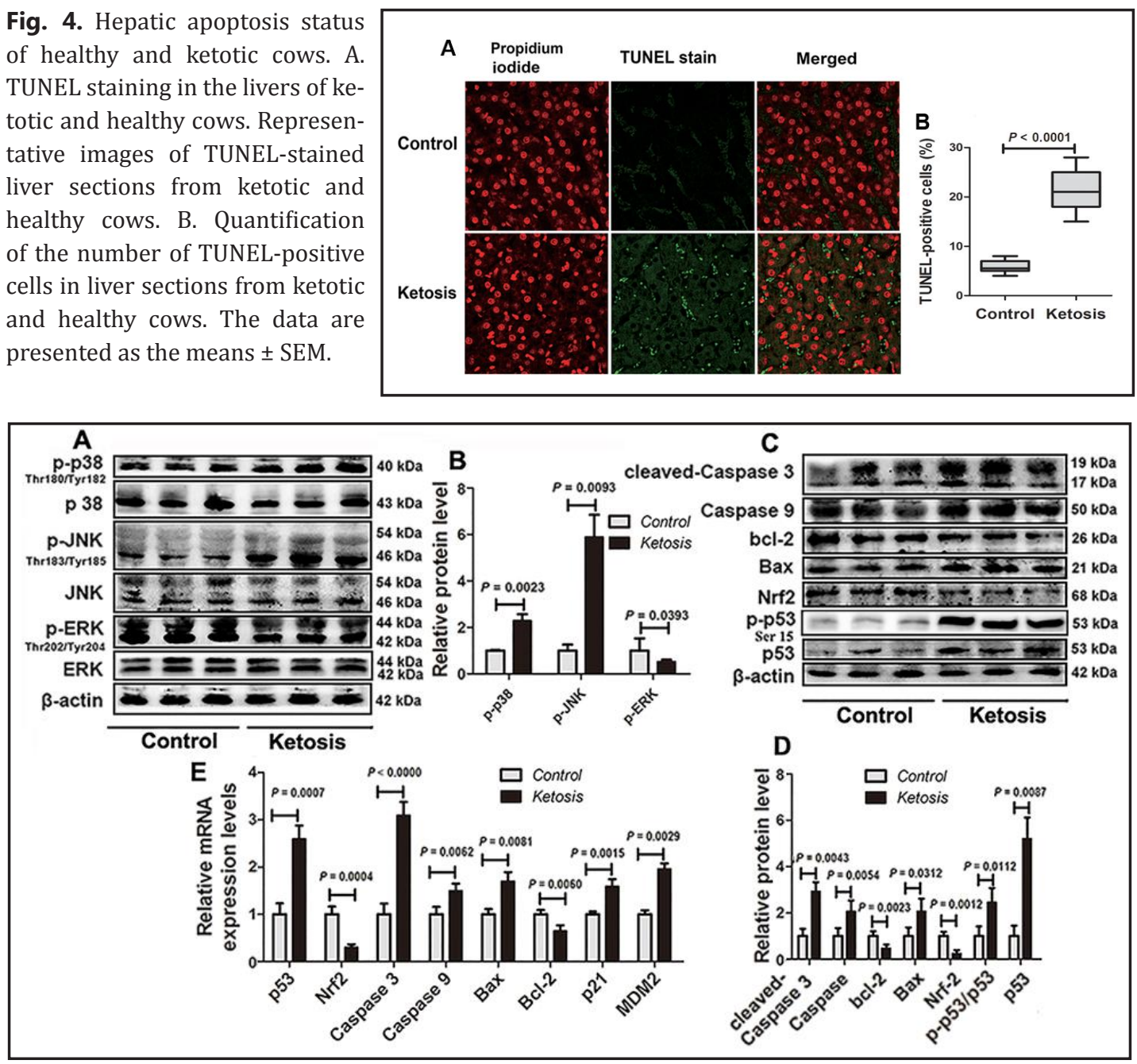

Fig. 5. The expression of molecules involved in apoptosis signaling pathway in dairy cows with ketosis. A: Western blots for p38MAPK, p-p38MAPK, JNK, p-JNK and ERK, p-ERK and $\beta$-actin in liver samples from ketotic $(n=10)$ and healthy cows $(n=10)$; B: Levels of phosphorylated p38MAPK, JNK and ERK in the livers of ketotic $(n=10)$ and healthy cows $(n=10)$. C: Western blots for cleaved-Caspase 3, Caspase 9, Bcl-2, Bax, Nrf2, phosphorylated p53 and p53 in liver samples from ketotic $(\mathrm{n}=10)$ and healthy cows $(\mathrm{n}=10)$; D: Relative expression levels of the cleaved-Caspase 3, Caspase 9, Bcl-2, Bax, Nrf2, phosphorylated p53 and p53 proteins in the livers of ketotic $(n=10)$ and healthy cows $(n=10)$; E: Expression levels of the Caspase 3, Caspase 9, Bcl-2, Bax, Nrf2, p53, p21 and MDM2 mRNAs in the livers of ketotic $(n=15)$ and healthy cows $(n=15)$. The data are presented as means \pm SEM. 


\section{Cellular Physiology Cell Physiol Biochem 2017;43:568-578 \begin{tabular}{l|l|l|} 
DOI: 10.1159/000480529 & $\begin{array}{l}\text { O 2017 The Author(s). Published by S. Karger AG, Basel } \\
\text { www.karger.com/cpb }\end{array}$
\end{tabular}

liver in ketotic cows. A significantly greater number of TUNEL-positive cells were observed in ketotic cows than in healthy cows (Fig. 4A and B). Based on these result, ketotic cows display severe hepatic apoptosis.

\section{Changes in apoptotic signaling pathways in ketotic cows}

We detected the levels of phosphorylated ERK1/2, JNK, and p38MAPK, and the protein and mRNA levels of apoptotic and anti-apoptotic molecule to investigate the role of MAPKs pathway in hepatic apoptosis in ketotic cows. As shown in Fig. 5A and B, the levels of phosphorylated JNK and p38MAPK were significantly increased $(P<0.01)$, whereas the levels of phosphorylated ERK1/2 were significantly decreased $(P<0.05)$ in the livers of ketotic cows. Furthermore, significantly higher levels of phosphorylated p53, p53 and apoptotic proteins cleaved-Caspase 3, Caspase 9 and Bax were observed in ketotic cows than in control cows (Fig. 5C and D; $P<0.05, P<0.01$ ). However, significantly lower levels of the Nrf2 protein and anti-apoptotic molecule Bcl-2 were observed in ketotic cows than in healthy cows (Fig. 5C and D; $P<0.01$ )., The mRNA levels of apoptotic and anti-apoptotic molecules were detected using qRT-PCR to further evaluate the hepatic apoptotic signaling pathway in ketotic cows. The levels of the p53, p21, MDM2, Caspase 3, Caspase 9 and Bax mRNAs were significantly increased in ketotic cows compared with healthy cows (Fig. 5E; $P<0.01)$. However, the levels of the $N r f 2$ and $B c l-2$ mRNAs were significantly decreased in ketotic cows (Fig. 5E; $P<0.01$ ). Taken together, hepatic MAPK pathways are over-induced and partially mediate the apoptotic damage in the liver of ketotic cows.

\section{Discussion}

Dairy cows with ketosis display oxidative stress and hepatic damage. However, hepatic apoptotic status has never been investigated in dairy cows with ketosis. In this study, we firstly found that the hepatic MAPK apoptosis pathways were over-induced in ketotic cows. More importantly, over-induced MAPK pathways partially mediated apoptotic damage in the liver of ketotic cows.

Postpartum dairy cows usually experience NEB due to increased energy demands and decreased dry matter intake. NEB initiates fat mobilization and subsequent increases in blood NEFA and ketone body concentrations [18]. Excess NEFAs are re-esterified into TG, causing hepatic fat accumulation. In our study, hepatic Oil red $\mathrm{O}$ and H\&E staining and TG measurements showed that ketotic cows displayed hepatic fat accumulation. Nevertheless, excessive hepatic fat accumulation may increase the inflammatory response. The concentrations of the inflammatory markers HP and SAA were markedly increased in ketotic cows in our study. Thus, ketotic cows exhibit hepatic fat accumulation and systemic inflammation.

Based on accumulation evidence, excess lipid accumulation promotes lipotoxicity and may induce hepatic injury and inflammation in mice by generating oxidative stress $[19,20]$. In addition, oxidative stress participates in the inflammatory response to liver disease in a variety of human conditions and experimental animal models [21,22]. According to clinical investigations and in vivo data, cows with ketosis display oxidative stress and associated with NEFAs and ketone body [23]. Unfortunately, the evaluation of the oxidative stress status of dairy cows has mainly been performed by determining the levels oxidative and antioxidative parameters in blood. In this study, liver biopsies were performed to measure the oxidative stress parameters. The hepatic MDA content was significantly increased, but the CAT, SOD, and GSH-Px activities were significantly reduced in ketotic cows compared with control cows. Based on these results, ketotic cows display severe hepatic oxidative stress. As shown in human and mouse studies, oxidative stress results in lipid peroxidation, DNA damage, mitochondrial dysfunction, and finally induce cell apoptosis and tissue injury [5]. We therefore determined the blood levels of the hepatic function indicators AST, ALT, GLDH, and GGT. The blood concentrations of AST, ALT, GLDH, and GGT were significantly increased 


\section{Cellular Physiology Cell Physiol Biochem 2017;43:568-578 \begin{tabular}{l|l} 
DOI: 10.1159/000480529 & $\begin{array}{l}\text { O } 2017 \text { The Author(s). Published by S. Karger AG, Basel } \\
\text { www.karger.com/cpb }\end{array}$
\end{tabular} \\ Du et al.: Hepatic Apoptosis Status in Dairy Cows with Ketosis}

in the ketotic cows, indicating ketotic cows displayed hepatic damage. Similarly, Li et al. also reported a significant increase in the blood AST and ALT levels in dairy cows with ketosis [3], further supporting our results.

Severe oxidative stress may induce apoptosis. In human, apoptosis is associated with several metabolic diseases, such as diabetes, obesity and NAFLD [24]. Similarly, oxidative stress and apoptosis are also involved in metabolic diseases of dairy cows. In the present study, we found that the blood concentration of apoptosis marker M30, hepatic Caspase 3 activity, and the number of TUNEL-positive cells were significantly increased in the ketotic cows. Thus, ketotic cows also display severe hepatic apoptosis. Hepatic apoptotic damage resulted from the oxidative stress-induced "second hit", and further impaired the metabolic function of liver cells.

Apoptosis is the major type of programmed cell death that occurs when DNA damage is irreparable, and it is mediated by many signaling pathways. Among the signaling pathways that respond to stress, MAPK family members are crucial for the maintenance of cell function, and are important signal transduction mediators that respond to a wide range of extracellular stresses, particularly oxidative stress [25]. Three subfamilies of MAPKs have been identified: ERK1/2, JNKs, and p38-MAPKs. ERKs were originally reported to be important for cell survival, whereas JNKs and p38-MAPKs were deemed stress-responsive MAPKs involved in apoptosis $[9,10]$. However, changes in hepatic MAPKs pathways have not been characterized in ketotic cows. In the present study, the levels of phosphorylated JNK and p38MAPK were significantly increased, but the levels of phosphorylated ERK1/2 were significantly decreased. Thus, the MAPK apoptotic pathways were involved in the hepatic apoptosis in ketotic cows. As shown in our previous studies, high levels of NEFA and a BHBA treatment significantly increased levels of phosphorylated p38MAPK and induced apoptosis in bovine hepatocytes in vitro $[26,27]$. Furthermore, according to Konishi et al., overactivation of JNK may promote human colon cancer cell apoptosis [28]. As shown in the study by Feng et al., ERK S-nitrosylation inhibits its phosphorylation and triggers the apoptotic program in MCF7 cells [29]. Thus, MAPK pathways play crucial roles in the induction of apoptosis. Therefore, the overactivation of JNK and p38MAPK and inhibition of ERK1/2 mediated the apoptotic damage in the liver of ketotic cows and further promoted the development of ketosis.

The activation of MAPKs regulates downstream redox-sensitive transcription factors, such as p53 and Nrf2, to control the expression of downstream pro-apoptotic and antiapoptotic genes [30,31]. Nrf2 regulates the transcription of a number of antioxidant enzymes by binding to the antioxidant response element (ARE) in the promoter regions of genes such as glutathione synthesis enzymes and thioredoxin-1, among others, and regulates the expression of the anti-apoptotic gene $\mathrm{Bcl}-2$. According to Niture and Jaiswal, the Nrf2 protein up-regulates the anti-apoptotic protein $\mathrm{Bcl}-2$ and prevents cellular apoptosis in human hepatoblastoma (HepG2) cells [32]. However, the expression of apoptosis-related molecules has never been measured in the liver of dairy cows with ketosis. In our study, the levels of phosphorylated p53 and p53 proteins were significantly increased, but the levels of the Nrf2 protein were significantly decreased. Importantly, the expression levels of the pro-apoptotic molecules p21, MDM2, cleaved-Caspase 3, Caspase 9 and Bax were significantly increased in ketotic cows compared with healthy cows. Conversely, the levels of the Bcl-2 mRNA and protein were significantly decreased. Based on these results, ketotic cows display severe hepatic apoptosis and MAPK-p53-Nrf2 apoptotic pathway is over induced.

In summary, ketotic cows display severe hepatic oxidative stress and apoptotic damage. The hepatic MAPK-p53-Nrf2 pathway is over induced, which partially mediates the hepatic apoptotic damage and further aggravates the ketosis.

\section{Acknowledgements}

This work was supported by the National key research and development program (Beijing, China; grant no. 2016YFD0501206), the National High Technology Research 


\section{Cellular Physiology Cell Physiol Biochem 2017;43:568-578 \\ \begin{tabular}{ll|l} 
and Biochemistry Published onlıne: September 21, 2017 & $\begin{array}{l}\text { C 2017 The Author(s). Published by S. Karger AG, Basel } \\
\text { www.karger.com/cpb }\end{array}$ \\
\hline
\end{tabular} \\ Du et al.: Hepatic Apoptosis Status in Dairy Cows with Ketosis}

and Development Program 863 (Beijing, China; grant no. 2013AA102806), the National Natural Science Foundation of China (Beijing, China; grant nos. 31402265, 31472247, and 31672621).

\section{Disclosure Statement}

The authors have no conflicts of interest to declare.

\section{References}

1 Sordillo LM, Aitken SL: Impact of oxidative stress on the health and immune function of dairy cattle. Vet Immunol Immunopathol 2009;128:104-109.

-2 Bobe G, Young JW, Beitz DC: Invited review: Pathology, etiology, prevention, and treatment of fatty liver in dairy cows *. J Dairy Sci 2004;87:3105-3124.

-3 Li Y, Ding H, Wang X, Feng S, Li XB, Wang Z, Liu G, Li X: An association between the level of oxidative stress and the concentrations of nefa and bhba in the plasma of ketotic dairy cows. J Anim Physiol Anim Nutr 2016;100:844-851.

4 Naito Y, Suematsu M, Yoshikawa T: Free Radical Biology in Digestive Diseases (eds). Front Gastrointest Res. Basel, Karger, 2011, vol 29, pp 144-155

5 Schieber M, Chandel NS: Ros function in redox signaling and oxidative stress. Curr Biol 2014;24:R453-R462.

6 Ji Y, Rong X, Li D, Cai L, Rao J, Lu Y: Inhibition of cartilage acidic protein 1 reduces ultraviolet b irradiation induced-apoptosis through p38 mitogen-activated protein kinase and jun amino-terminal kinase pathways. Cell Physiol Biochem 2016;39:2275-2286.

7 Zhang C, Liu S, Yuan X, Hu Z, Li H, Wu M, Yuan J, Zhao Z, Su J, Wang X: Valproic acid promotes human glioma u87 cells apoptosis and inhibits glycogen synthase kinase-3 $\beta$ through erk/akt signaling. Cell Physiol Biochem 2016;39:2173-2185.

-8 Chen Z, Zhang X, Liu Y, Liu Z: Morphine postconditioning protects against reperfusion injury via inhibiting jnk/p38 mapk and mitochondrial permeability transition pores signaling pathways. Cell Physiol Biochem 2016;39:61-70.

-9 Odaka H, Numakawa T, Yoshimura A, Nakajima S, Adachi N, Ooshima Y, Inoue T, Kunugi H: Chronic glucocorticoid exposure suppressed the differentiation and survival of embryonic neural stem/progenitor cells: Possible involvement of erk and pi3k/akt signaling in the neuronal differentiation. Neurosci Res 2016;113:28.

10 Yao J, Weng Y, Yan S, Hou M, Wang H, Shi Q Zuo G: Nov inhibits proliferation while promoting apoptosis and migration in osteosarcoma cell lines through p38/mapk and jnk/mapk pathways. Oncol Rep 2015;34:20112021.

11 Qi G, Chen J, Shi C, Wang Y, Mi S, Shao W, Yu X, Ma Y, Ling J, Huang J: Cinnamic acid (cinn) induces apoptosis and proliferation in human nasopharyngeal carcinoma cells. Cell Physiol Biochem 2016;40:589-596.

12 Bo H, Wu Y, Jie L, Shen X, Fei T, Xu G, Shen R: Gsk-3beta inhibitor induces expression of nrf2/trxr2 signaling pathway to protect against renal ischemia/reperfusion injury in diabetic rats. Kidney Blood Press Res 2016;41:937-946.

-13 Du X, Shi Z, Peng Z, Zhao C, Zhang Y, Wang Z, Li X, Liu G, Li X: Acetoacetate induces hepatocytes apoptosis by the ros-mediated mapks pathway in ketotic cows. J Cell Physiol 2017;9999:1-13.

14 Tharwat M, Takamizawa A, Hosaka YZ, Endoh D, Oikawa S: Hepatocyte apoptosis in dairy cattle during the transition period. Can J Vet Res 2012;76:241-247.

15 Tharwat M, Endoh D, Oikawa S: Hepatocyte apoptosis in dairy cows with fatty infiltration of the liver. Res Vet Sci 2012;93:1281-1286.

16 Itle AJ, Huzzey JM, Weary DM, Keyserlingk MAGV: Clinical ketosis and standing behavior in transition cows. J Dairy Sci 2015;98:128-134.

17 Mcart JA, Nydam DV, Oetzel GR: Epidemiology of subclinical ketosis in early lactation dairy cattle. J Dairy Sci 2012;95:5056-5066. 


\section{Cellular Physiology Cell Physiol Biochem 2017;43:568-578

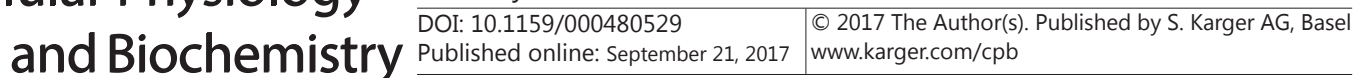 \\ Du et al.: Hepatic Apoptosis Status in Dairy Cows with Ketosis}

18 Li X, Huang W, Gu J, Du X, Lei L, Yuan X, Sun G, Wang ZL, Li X, Liu G: Srebp-1c overactivates ros-mediated hepatic nf-kb inflammatory pathway in dairy cows with fatty liver. Cell Signal 2015;27:2099-2109.

19 Satapati S, Kucejova B, Duarte J, Fletcher JA, Reynolds L, Sunny NE, He T, Nair LA, Livingston K, Fu $\mathrm{X}$ : Mitochondrial metabolism mediates oxidative stress and inflammation in fatty liver. J Clin Invest 2015;125:1605-1605.

20 Nguyen D, Samson SL, Reddy VT, Gonzalez EV, Sekhar RV: Impaired mitochondrial fatty acid oxidation and insulin resistance in aging: Novel protective role of glutathione. Aging Cell 2013;12:415-425.

21 Greenhalgh SN, Thompson AI, Henderson NC, Iredale JP: Oxidative stress and liver inflammation; in Parola EAM (eds): Studies on hepatic disorders. Switzerland, Springer International Publishing, 2015, Part II, pp 123-147.

22 Shi X, Li D, Deng Q Li Y, Sun G, Yuan X, Song Y, Wang ZL, Li X, Li X: Nefas activate the oxidative stressmediated nf-kappab signaling pathway to induce inflammatory response in calf hepatocytes. J Steroid Biochem Mol Biol 2015;145:103-112.

23 Sharma N, Singh N, Singh O, Pandey V, Verma P: Oxidative stress and antioxidant status during transition period in dairy cows. Asian-Australas J Anim Sci 2011;24:479-484.

24 Takaki A, Kawai D, Yamamoto K: Multiple hits, including oxidative stress, as pathogenesis and treatment target in non-alcoholic steatohepatitis (nash). Int J Mol Sci 2013;14:20704-20728.

25 Rains JL, Jain SK: Oxidative stress, insulin signaling, and diabetes. Free Radic Biol Med 2011;50:567-575.

26 Song Y, Li X, Li Y, Li N, Shi X, Ding H, Zhang Y, Li X, Liu G, Wang Z: Non-esterified fatty acids activate the rosp38-p53/nrf2 signaling pathway to induce bovine hepatocyte apoptosis in vitro. Apoptosis 2014;19:984997.

-27 Song Y, Li N, Gu J, Fu S, Peng Z, Zhao C, Zhang Y, Li X, Wang Z, Li X: $\beta$-hydroxybutyrate induces bovine hepatocyte apoptosis via an ros-p38 signaling pathway. J Dairy Sci 2016;99:9184-9198.

28 Konishi H, Fujiya M, Tanaka H, Ueno N, Moriichi K, Sasajima J, Ikuta K, Akutsu H, Tanabe H, Kohgo Y: Probiotic-derived ferrichrome inhibits colon cancer progression via jnk-mediated apoptosis. Nat Commun 2016;7:12365.

29 Feng X, Sun T, Bei Y, Ding SY, Zheng W, Lu Y, Shen P: S-nitrosylation of erk inhibits erk phosphorylation and induces apoptosis. Sci Rep 2013;3:1814-1814.

-30 Sakata S, Hayashi S, Fujishiro T, Kawakita K, Kanzaki N, Hashimoto S, Iwasa K, Chinzei N, Kihara S, Haneda M: Oxidative stress-induced apoptosis and matrix loss of chondrocytes is inhibited by eicosapentaenoic acid. J Orthop Res 2015;33:359-365.

-31 Mittal SPK, Khole S, Jagadish N, Ghosh D, Gadgil VR, Sinkar VP, Ghaskadbi SS: Andrographolide protects liver cells from h2o2 induced cell death by upregulation of nrf-2/ho-1 mediated via adenosine a2a receptor signalling. Biochim Biophys Acta 2016;1860:2377-2390.

-32 Niture SK, Jaiswal AK: Nrf2 protein up-regulates antiapoptotic protein bcl-2 and prevents cellular apoptosis. J Biol Chem 2012;287:9873-9886. 